Fixed Point Theory, 21(2020), No. 2, 525-548

DOI: $10.24193 /$ fpt-ro.2020.2.38

http://www.math.ubbcluj.ro/ nodeacj/sfptcj.html

\title{
EXISTENCE OF THREE WEAK SOLUTIONS FOR KIRCHHOFF-TYPE PROBLEMS WITH VARIABLE EXPONENT AND NONHOMOGENEOUS NEUMANN CONDITIONS
}

\author{
S. HEIDARKHANI*, A.L.A. DE ARAUJO**, G.A. AFROUZI*** AND S. MORADI*** \\ *Department of Mathematics, Faculty of Sciences, Razi University, 67149 Kermanshah, Iran \\ E-mail: s.heidarkhani@razi.ac.ir \\ ** Departamento de Matemática, Universidade Federal de Viçosa, 36570-000, Viçosa (MG), Brazil \\ E-mail: anderson.araujo@ufv.br \\ *** Department of Mathematics, Faculty of Mathematical Sciences, University of Mazandaran, \\ Babolsar, Iran \\ E-mail: afrouzi@umz.ac.ir, shahin.moradi86@yahoo.com
}

Abstract. We study the existence of at least three weak solutions for a class of differential equations with $p(x)$-Kirchhoff-type and subject to perturbations of nonhomogeneous Neumann conditions. Our technical approach is based on variational methods. Some applications and examples illustrate the obtained results.

Key Words and Phrases: Variable exponent Sobolev spaces, $p(x)$-Kirchhoff-type problems, three weak solutions, variational methods.

2010 Mathematics Subject Classification: 35J20, 35J60, 47H10.

\section{REFERENCES}

[1] G.A. Afrouzi, A. Hadjian, S. Heidarkhani, Steklov problem involving the $p(x)$-Laplacian, Electronic J. Differ. Equ., 2014(2014), no. 134, 1-11.

[2] S.N. Antontsev, J.F. Rodrigues, On stationary thermo-rheological viscous flows, Ann. Univ. Ferrara Sez. VII Sci. Mat., 52(2006), 19-36.

[3] S.N. Antontsev, S.I. Shmarev, A model porous medium equation with variable exponent of nonlinearity: existence, uniqueness and localization properties of solutions, Nonlinear Anal. TMA, 60(2005), 515-545.

[4] G. Autuori, F. Colasuonno, P. Pucci, Blow up at infinity of solutions of polyharmonic Kirchhoff systems, Complex Var. Elliptic Eqs., 57(2012), 379-395.

[5] G. Autuori, F. Colasuonno, P. Pucci, Lifespan estimates for solutions of polyharmonic Kirchhoff systems, Math. Mod. Meth. Appl. Sci., 22(2012), 1150009 [36 pages].

[6] G. Autuori, F. Colasuonno, P. Pucci, On the existence of stationary solutions for higher-order p-Kirchhoff problems, Commun. Contemp. Math., 16(2014), 1450002 [43 pages].

[7] D. Averna, G. Bonanno, Three solutions for a Neumann boundary value problem involving the p-Laplacian, Le Matematiche, 60(2006), 81-91.

[8] G. Bonanno, P. Candito, Non-differentiable functionals and applications to elliptic problems with discontinuous nonlinearities, J. Differ. Equ., 244(2008), 3031-3059. 
[9] G. Bonanno, P. Candito, Three solutions to a Neumann problem for elliptic equations involving the p-Laplacian, Arch. Math. (Basel), 80(2003), 424-429.

[10] G. Bonanno, A. Chinnì, Existence and multiplicity of weak solutions for elliptic Dirichlet problems with variable exponent, J. Math. Anal. Appl., 418(2014), 812-827.

[11] G. Bonanno, A. Chinnì, Multiple solutions for elliptic problems involving the $p(x)$-Laplacian, Le Matematiche, LXVI(2011), Fasc. I, 105-113.

[12] G. Bonanno, G. D'Aguì, Multiplicity results for a perturbed elliptic Neumann problem, Abstr. Appl. Anal., 2010(2010), DOI: 10.1155/2010/564363, 10 pages.

[13] G. Bonanno, S.A. Marano, On the structure of the critical set of non-differentiable functions with a weak compactness condition, Appl. Anal., 89(2010), 1-10.

[14] F. Cammaroto, A. Chinnì, B. Di Bella, Multiple solutions for a Neumann problem involving the $p(x)$-Laplacian, Nonlinear Anal. TMA, 71(2009), 4486-4492.

[15] F. Cammaroto, L. Vilasi, Existence of three solutions for a degenerate Kirchhoff-type transmission problem, Num. Func. Anal. Opt., 35(2014), 911-931.

[16] F. Cammaroto, L. Vilasi, Multiple solutions for a Kirchhoff-type problem involving the $p(x)$ Laplacian operator, Nonlinear Anal. TMA, 74(2011), 1841-1852.

[17] Y. Chen, S. Levine, M. Rao, Variable exponent, linear growth functionals in image restoration, SIAM J. Appl. Math., 66(2006), 1383-1406.

[18] N.T. Chung, Multiplicity results for a class of $p(x)$-Kirchhoff type equations with combined nonlinearities, Electronic J. Qual. Theory Differ. Equ., 2012(2012), 1-13.

[19] F. Colasuonno, P. Pucci, Multiplicity of solutions for $p(x)$-polyharmonic elliptic Kirchhoff equations, Nonlinear Anal. TMA, 74(2011), 5962-5974.

[20] G. D'Aguì, S. Heidarkhani, G. Molica Bisci, Multiple solutions for a perturbed mixed boundary value problem involving the one-dimensional p-Laplacian, Electronic J. Qual. Theory Differ Equ., 24(2013), 1-14.

[21] G. D'Aguì, A. Sciammetta, Infinitely many solutions to elliptic problems with variable exponent and nonhomogeneous Neumann conditions, Nonlinear Anal. TMA, 75(2012), 5612-5619.

[22] G. Dai, R. Hao, Existence of solutions for a p(x)-Kirchhoff-type equation, J. Math. Anal. Appl., 359(2009), 275-284.

[23] G. Dai, J. Wei, Infinitely many non-negative solutions for a $p(x)$-Kirchhoff-type problem with Dirichlet boundary condition, Nonlinear Anal. TMA, 73(2010), 3420-3430.

[24] A.L.A. De Araujo, S. Heidarkhani, G.A. Afrouzi, S. Moradi, A variational approach for nonlocal problems with variable exponent and nonhomogeneous Neumann conditions, preprint.

[25] A.L.A. De Araujo, S. Heidarkhani, G. Caristi, A. Salari, Multiplicity results for nonlocal problems with variable exponent and nonhomogeneous Neumann conditions, preprint.

[26] S.G. Deng, A local mountain pass theorem and applications to a double perturbed $p(x)$-Laplacian equations, Appl. Math. Comput., 211(2009), 234-241.

[27] X.L. Fan, On nonlocal p(x)-Laplacian Dirichlet problems, Nonlinear Anal. TMA, 72(2010), 3314-3323.

[28] X.L. Fan, C. Ji, Existence of infinitely many solutions for a Neumann problem involving the $p(x)$-Laplacian, J. Math. Anal. Appl., 334(2007), 248-260.

[29] X.L. Fan, D. Zhao, On the spaces $L^{p(x)}(\Omega)$ and $W^{m, p(x)}(\Omega)$, J. Math. Anal. Appl., 263(2001) 424-446.

[30] J.R. Graef, S. Heidarkhani, L. Kong, A variational approach to a Kirchhoff-type problem involving two parameters, Results Math., 63(2013), 877-889.

[31] T.C. Halsey, Electrorheological fluids, Science, 258(1992), 761-766.

[32] P. Harjulehto, P. Hästö, An overview of variable exponent Lebesgue and Sobolev spaces, in: D. Herron (Ed.), Future Trends in Geometric Function Theory, RNC Workshop, Jyväskylä, 2003, 85-93.

[33] S. Heidarkhani, G.A. Afrouzi, A. Hadjian, Multiplicity results for elliptic problems with variable exponent and nonhomogeneous Neumann conditions, Math. Meth. Appl. Sci., 38(2015), 25892599. 
[34] S. Heidarkhani, A.L.A. De Araujo, G.A. Afrouzi, S. Moradi, Multiple solutions for Kirchhofftype problems with variable exponent and nonhomogeneous Neumann conditions, Math. Nach., 291(2018), 326-342.

[35] M. Hssini, M. Massar, N. Tsouli, Existence and multiplicity of solutions for a p(x)-Kirchhoff type problems, Bol. Soc. Paran. Mat., 33(2015), 201-215.

[36] E.M. Hssini, N. Tsouli, M. Haddaoui, Existence and multiplicity solutions for a $(p(x), q(x))$ Kirchhoff type systems, Le Matematiche, LXXI(2016), Fasc. I, 75-88.

[37] G. Kirchhoff, Vorlesungen uber Mathematische Physik: Mechanik, Teubner, Leipzig, 1883.

[38] O. Kováčik, J. Rákosník, On the spaces $L^{p(x)}(\Omega)$ and $W^{1, p(x)}(\Omega)$, Czechoslovak Math., 41(1991), 592-618.

[39] J.L. Lions, On some questions in boundary value problems of mathematical physics, In: Contemporary Developments in Continuum Mechanics and Partial Differential Equations (Proc. Internat. Sympos. Inst. Mat. Univ. Fed. Rio de Janeiro, 1977), North-Holland Math. Stud, 30(1978), 284-346.

[40] M. Massar, M. Talbi, N. Tsouli, Multiple solutions for nonlocal system of $(p(x), q(x))$-Kirchhoff type, Appl. Math. Comput., 242(2014), 216-226.

[41] M. Mihăilescu, Existence and multiplicity of solutions for a Neumann problem involving the $p(x)$-Laplacian operator, Nonlinear Anal. TMA, 67(2007), 1419-1425.

[42] G. Molica Bisci, V. Rădulescu, Applications of local linking to nonlocal Neumann problems, Commun. Contemp. Math., 17(2014), 1450001 [17 pages].

[43] G. Molica Bisci, V. Rădulescu, Mountain pass solutions for nonlocal equations, Annales AcademiæScientiarum FennicæMathematica, 39(2014), 579-59.

[44] G. Molica Bisci, V. Rădulescu, R. Servadei, Variational Methods for Nonlocal Fractional Problems, Encyclopedia of Mathematics and its Applications, vol. 162, Cambridge University Press, Cambridge, 2016.

[45] D.S. Moschetto, A quasilinear Neumann problem involving the $p(x)$-Laplacian, Nonlinear Anal. TMA, 71(2009), 2739-2743.

[46] C. Pfeiffer, C. Mavroidis, Y. Bar-Cohen, B. Dolgin, Electrorheological fluid based force feedback device, in: Proceedings of the 1999 SPIE Telemanipulator and Telepresence Technologies VI Conference (Boston, MA), 3840(1999), 88-99.

[47] C. Qian, Z. Shen, M. Yang, Existence of solutions for $p(x)$-Laplacian nonhomogeneous Neumann problems with indefinite weight, Nonlinear Anal. RWA, 11(2010), 446-458.

[48] V. Rădulescu, Nonlinear elliptic equations with variable exponent: old and new, Nonlinear Anal. TMA, 121(2015), 336-369.

[49] V. Rădulescu, D. Repovš, Partial Differential Equations with Variable Exponents, Variational Methods and Qualitative Analysis, Monographs and Research Notes in Mathematics, CRC Press, Boca Raton, FL, 2015.

[50] D. Repovš, Stationary waves of Schrödinger-type equations with variable exponent, Anal. Appl., 13(2015), 645-661.

[51] B. Ricceri, On an elliptic Kirchhoff-type problem depending on two parameters, J. Global Optim., 46(2010), 543-549.

[52] M. Ružička, Electro-rheological Fluids: Modeling and Mathematical Theory, Lecture Notes in Math., 1784, Springer, Berlin, 2000.

[53] S. Samko, On a progress in the theory of Lebesgue spaces with variable exponent maximal and singular operators, Integral Transforms Spec. Funct., 16(2005), 461-482.

[54] Z. Shen, C. Qian, Infinitely many solutions for a Kirchhoff-type problem with non-standard growth and indefinite weight, Z. Angew. Math. Phys., 66(2015), 399-415.

[55] J. Simon, Régularité de la solution d'une équation non linéaire dans $\mathbb{R}^{N}$, Lecture Notes in Math. Springer, Berlin, Heidelberg, 665(1978), 205-227.

[56] L. Vilasi, Eigenvalue estimates for stationary $p(x)$-Kirchhoff problems, Electronic J. Differ. Equ., 2016(2016), no. 186, 1-9.

[57] E. Zeidler, Nonlinear Functional Analysis and its Applications, II/B, Springer-Verlag, New York, 1990. 
[58] V.V. Zhikov, Averaging of functionals of the calculus of variations and elasticity theory, Math. USSR Izv., 9(1987), 33-66.

Received: April 14, 2018; Accepted: September 6, 2018. 
